\title{
The effect of low level laser on number of Candida albicans colonies in-vitro: a new finding
}

\author{
Shamsoulmolouk Najafi ${ }^{1,2}$, Nafiseh Sheykhbahaei ${ }^{1,2}$, Mina khayamzadeh ${ }^{1,2}$ and Narges Gholizadeh ${ }^{1,2^{*}}$ (1)
}

\begin{abstract}
Background: Candida albicans is a commensal organism that causes a wide variety of diseases in humans. One of these diseases is oral candidiasis, which occurs at a high recurrence rate in spite of available treatments. The purpose of this study was to compare the effect of low-level laser therapy (LLLT) with the use of nystatin on in-vitro growth of Candida albicans.

Method: We prepared two samples of Candida albicans at different concentrations: $10^{4}$ viable cells $/ \mathrm{ml}$ and $10^{6}$ viable cells/ml. Specimens from each sample were divided into a control group, a nystatin-treated group, and a group treated with LLLT. The control group was cultured without any intervention. The second group was treated with nystatin and the solution was vibrated for $30 \mathrm{~s}$ or $60 \mathrm{~s}$. The third group was irradiated with a galliumaluminum-argon (Ga-Al-Ar) diode laser (Epic 10; Biolase Inc.)in continuous mode using a wavelength of $940 \mathrm{~nm}$ and a power of $1 \mathrm{~W}$ for $30 \mathrm{~s}$ or $60 \mathrm{~s}\left(38 \mathrm{~J} / \mathrm{cm}^{2}\right.$ and $\left.76 \mathrm{~J} / \mathrm{cm}^{2}\right)$. The specimens from the nystatin group and the LLLT group were cultured and the number of colony-forming units (CFU/ml) for each group was counted and compared.
\end{abstract}

Results: Nystatin completely eliminated the colonies (0 colonies) in all specimens. There was an increase in the number of colonies in the LLLT group for both cell concentrations at $30 \mathrm{~s}$ and at $60 \mathrm{~s}$. However, this increase was statistically significant only for a concentration of $10^{4}$ viable cell $\mathrm{s} / \mathrm{ml}$ at an exposure time of 30s. The increase in the concentration of $10^{6}$ viable cell $\mathrm{s} / \mathrm{ml}$ at both $30 \mathrm{~s}$ and $60 \mathrm{~s}$ was statistically significant compared with the control group, although the highest number of colonies remained after an exposure time of 60s.

Conclusion: LLLT led to an increase in the growth of Candida colonies. However, there was no significant difference related to the exposure time between the different cell concentrations.

Keywords: Low-Level laser therapy, Nystatin, Candida albicans

\section{Background}

There are different species of Candida that are known to cause infection in the oral cavity of humans. Candida albicans (C. albicans) is the most common pathogen associated with oral candidiasis [1]. Several conditions increase a person'srisk of oral candidiasis, including senescence, immunosuppression, organ transplantation, diabetes mellitus, long-term use of corticosteroids, the use of broad-spectrum antibiotics, and wearing dentures

\footnotetext{
* Correspondence: n.gholizadeh88@gmail.com

${ }^{1}$ Dental research center, Tehran University of Medical Science, Tehran, Iran

${ }^{2}$ Oral \& Maxillofacial Medicine, School of Dentistry, Tehran University of

Medical Science, Tehran, Iran
}

[2]. The high incidence rate of oral candidiasis is related to the ability of $C$. albicans to adapt to various environments in the host's oral cavity [3]. Candidiasis and morbidity associated with candidiasis have become more prevalent as the population ages and the numbers of people who have compromised immune systems increase [1-8].

Candida can cause denture stomatitis, a chronic inflammatory condition that occurs especially in the palatal mucosa of people who wearill-fitting dentures [9]. This condition occurs in approximately one third to two thirds of people who wear full dentures [10]. It is believed that the prevalence of denture stomatitis is higher in women than in men [11]. The treatment of denture stomatitis is

(c) The Author(s). 2019 Open Access This article is distributed under the terms of the Creative Commons Attribution 4.0 International License (http://creativecommons.org/licenses/by/4.0/), which permits unrestricted use, distribution, and reproduction in any medium, provided you give appropriate credit to the original author(s) and the source, provide a link to the Creative Commons license, and indicate if changes were made. The Creative Commons Public Domain Dedication waiver (http://creativecommons.org/publicdomain/zero/1.0/) applies to the data made available in this article, unless otherwise stated. 
rather complicated because of the multifactorial nature of the disease. Conventional treatments include improving oral hygiene, using antiseptic mouthwash, removing the dentures at night and placing them in a disinfectant solution, and replacing ill-fitted dentures. Nystatin is an antifungal agent that commonly used to treat denture stomatitis [12].

Nystatin is from the Polyenes family that acts by binding to ergosterol, which is one of the major constituents of the fungal cell wall. It can also bind to cholesterol in the cytoplasmic membrane of the host cells. Unfortunately, the use of nystatin is associated with side effects, including diarrhea, abdominal pain, tachycardia, bronchospasm, facial swelling, muscle pain, Stevens-Johnson syndrome, itching, burning sensations, and rashes [13]. The longterm use of nystatin not only requires the patients cooperation, but it can also lead to the development of drugresistant strains of $C$. albicans [14]. In addition, the drug is relatively expensive $[15,16]$. It is believed that the diluting effect of saliva affects the bioavailability of oral antifungal agents, which may cause therapy failure or the recurrence of infection [5].

Current research is being done on other treatment strategies for oral candidiasis. For example, laser therapy is used to change tissue metabolism, which accelerates wound healing, eradicates infectious organisms, and decreases pain and inflammation [17-19]. Low-level laser therapy (LLLT) uses a gallium-aluminum-argon (Ga-AlAr) diode laser with a short $10-\mu$ s pulse to control the amount of energy that reaches the exposed tissues. LLLT is also well tolerated by the patient, causes less damage to the surrounding tissues, and provides better healing of the lesions [20].

In this study, a high-power Ga-Al-Ar diode laser with a wavelength of $940 \mathrm{~nm}$ at $1 \mathrm{~W}$ was used. The aim of the study was to evaluate the effects of the laser using a safe wavelength of $940 \mathrm{~nm}$ against colonies of C. albicans.

\section{Methods}

A standard strain of C. albicans, ATCC18804 [21], was purchased from the Microbiology Research Center, Pasteur Institute of Iran, Tehran, Iran. To prepare the specific concentrations of the strain, we first diluted the samples using sterile saline $(0.85 \% \mathrm{NaCl})$ to achieve a concentration of $1.5 \times 10^{8}$ viable cells $/ \mathrm{ml}$. We then adjusted the concentration to 0.5 McFarland turbidity standard solution and cultured the samples on Sabouraud dextrose agar. Finally, we reserved and incubated all the prepared samples at $37{ }^{\circ} \mathrm{C}$ for $24 \mathrm{~h}$. At the end of this period, two different concentrations of Candida colonies were obtained. Sample A contained $10^{4}$ viable cells $/ \mathrm{ml}$, while sample B contained $10^{6}$ viable cells $/ \mathrm{ml}$. A total of 72 specimens, 36 from sample A and 36 from sample B, were prepared. Twelve specimens from eachsample were then randomly classified into one of the three subgroups shown in Table 1. Group 1 was the control group. Group 2 was treated with 100,000 units/ml of nystatin. Group 3 was treated with LLLT at a wavelength of 940 $\mathrm{nm}$. All the samples were coded before the appropriate interventions.

\section{Control group}

The control group consisted of 12 specimens from sample A and 12 from sample B; thus, there were 24 specimens in total. The specimens were cultured to ensure that the C. albicans were able to grow in vitro (Table 1).

\section{Nystatin group}

The nystatin group consisted of $10 \mathrm{ml}$ nystatin suspension added to 12 specimens from sample A and 12 specimens from sample B. The solutions were immediately mixed in a vibrator; six specimens from each sample were vibrated for 30s and six specimens from each sample were vibrated for 60 s (Table 1). The specimens were then cultured in Sabouraud dextrose agar. After incubating the cultures for $48 \mathrm{~h}$ at $37^{\circ} \mathrm{C}$, the number of colonies of $C$. albicans per plate was measured using the colony-forming units $(\mathrm{CFU} / \mathrm{ml})$. The two investigators who counted the number of colonies were blinded to the intervention.

\section{LLLTgroup}

AGa-Al-Ardiode laser (Epic 10; Biolase Inc.) with a wavelength of $940 \mathrm{~nm}$ at $1 \mathrm{~W}$ was used in this study. The laser was pre-configured and required no calibration. The diagonal head probe was $1 \mathrm{~cm}$ in diameter. Twelve specimens each from sample A and sample B were exposed to the laser irradiation. Six specimens from each sample were exposed for $30 \mathrm{~s}\left(38 \mathrm{~J} / \mathrm{cm}^{2}\right)$, while six from each sample were exposed for $60 \mathrm{~s}\left(76 \mathrm{~J} / \mathrm{cm}^{2}\right)$ (Table 1). Similar to the nystatin group, all specimens were

Table 1 Number of candida colonies in different initial concentration

\begin{tabular}{rllllll}
\hline Base & & N & Min & Max & Mean & SD \\
\hline $10^{4}$ & control & 12 & 220.00 & 720.00 & 403.3333 & 172.24014 \\
& Nystatin 30s & 6 & NA & NA & NA & NA \\
Nystatin60s & 6 & NA & NA & NA & NA \\
LLLT 30s & 6 & 520.00 & 1240.00 & 946.6667 & 286.12352 \\
& LLLT 60s & 6 & 380.00 & 880.00 & 636.6667 & 203.73185 \\
$10^{6}$ Control & 12 & 2320.00 & $31,120.00$ & $15,700.00$ & $11,165.13860$ \\
& Nystatin 30s & 6 & NA & NA & NA & NA \\
Nystatin 60s & 6 & NA & NA & NA & NA \\
LLLT 30s & 6 & $20,100.0$ & $48,160.00$ & $33,816.6667$ & 9649.97340 \\
LLLT 60s & 6 & $31,060.0$ & $45,280.00$ & $38,056.6667$ & 5887.21213 \\
\hline
\end{tabular}

$N$ number of specimens, SD Standard Deviation, NA Not Available 
cultured, encoded, and incubated. The number of colonies was determined by two investigators blinded to the intervention.

Once the specimens had been decoded, the data were analyzed using SPSS program, version 20. Because the data from this study were nonparametric, we applied the nonparametric tests (NPAR test) and the Kruskal-Wallis test to compare the variables. We also used repeated measures ANOVA (Analysis of variance) and the post hoc test to compare the data obtained from the different concentrations of Candida colonies, type of intervention, and time of exposure.

\section{Results}

In this study, 36 specimens from sample A $\left(10^{4}\right.$ viable cells $/ \mathrm{ml})$ and 36 specimens from sample B $\left(10^{6}\right.$ viable cells $/ \mathrm{ml}$ ) were each divided into three groups: a control group, a nystatin-treated group, and aLLLT group. A total of 72 specimens was used; each group contained 12 specimens. All groups were studied at $30 \mathrm{~s}$ and $60 \mathrm{~s}$.

In the nystatin group, the number of colonies from sample A and sample B significantly decreased at 30s and 60s compared with the control and LLLT groups. The nystatin completely eliminated the colonies $(0 \mathrm{col}-$ onies), regardless of the concentration or vibration period (time of exposure).

In the LLLT group, the number of colonies from sample A and sample B increased at 30s and 60s. However, this increase was only statistically significant compared with the sample A and control group at an exposure time of 30s. The increase in sample B at both $30 \mathrm{~s}$ and $60 \mathrm{~s}$ was statistically significant compared with the control group, although the highest number of colonies was found after the $60 \mathrm{~s}$ exposure to the laser (Tables 2 and 3)

\section{Discussion}

Few investigations have evaluated the effect of LLLT on the behavior of colonies of C. albicans. Based on a review of the literature, we did not find any studies that hadsimilar results to our study on C. albicans. We did find two studies that reported that LLLT caused an increase in bacterial proliferation [22] and an increase in squamous carcinoma cell lines [23]. Nussbaum et al.
(2002) showed that bacterial proliferation significantly increased after LLLT using a 3-W diode laser at a wavelength of $810 \mathrm{~nm}$, the laser was used in continuous mode at an intensity of $1 \mathrm{~J} / \mathrm{cm}^{2}$ [22]. Henriques et al. (2014) investigated the effects of LLLT on the expression of several tumor markers including $\beta$-catenin, MMP-9, cyclin D1 and E-cadherin, in a squamous carcinoma cell line [23]. They applied diode laser at a wavelength of $660 \mathrm{~nm}$ and energy densities of $0.5 \mathrm{~J} / \mathrm{cm}^{2}$ and $1.0 \mathrm{~J} / \mathrm{cm}^{2}$. The researchers found that alterations in the expression of tumor markers by LLLT had a stimulatory effect on the proliferation and invasion of SCC cells [23]. Generally, the results of these two studies were consistent with our results, which showed that LLLT caused an increase in the growth of the organism by unknown mechanisms.

These results obtained in this study ofthe LLLTon $C$. albicans may be related to such variables as levels and doses of energy, power, and power density, as well as the wavelength, method of application of laser (contact or non-contact and pulsed or continuous modes), contamination with other microorganisms, and time of the exposure. For example, red light is more effective than an infrared laser on pro-inflammatory effects or the growth of organisms because of the greater absorption of red light at a shorter wavelength by the photoreceptor (cytochrome $\mathrm{C}$ oxidase). A reason for the results of this study could be that the laser caused the acceleration of the electron transport chain in the mitochondria, which led to a higher rate of Adenosine triphosphate (ATP) production [18]. In addition, the exact mechanism for the differences seen between pulsed and continuous mode of LLLT has not yet been determined. In pulsed mode, the tissues are affected by a series of pulses in which the thermal energy increases with each period of radiation (pulse) because of the thermal energy remaining from the previous pulse. Thus, in pulsed mode, there is a higher level of heat inside the tissue than during continuous mode, which increases the damage to the tissue. In continuous mode, the dissemination of thermal energy prevent the accumulation of excess heat in the tissue [22]. Another reason for the results in this study could relate to the use of a high-power diode laser $>0.5$ W). High-power laser therapy delivers high energy to the tissue and causes photochemical effects through the

Table 2 Effect of different time on number of colonies at concentration of $10^{4}$

\begin{tabular}{llllll}
\hline Groups comparison & $\begin{array}{l}\text { Mean } \\
\text { difference } \\
(\mathrm{I}-\mathrm{J})\end{array}$ & SD error & Pvalue & 95\% IC \\
\cline { 4 - 6 } & 543.33333 & 136.34108 & $.011^{*}$ & 136.2113 & Upper bound \\
\hline Laser 30s to Control & 233.33333 & 108.91383 & .166 & 79.8548 & 950.4553 \\
Laser 60s to control & 310.00000 & 143.39534 & 166 & -108.7890 & 546.5215 \\
Laser 30s to Laser 60s & 3100 & 728.7890 \\
\hline
\end{tabular}

*: $(P$ value $\leq 0.05)$

Applied tests in these tables: Repeated measured ANOVA, POST HOC 
Table 3 Effect of different time on number of colonies at concentration of $10^{6}$

\begin{tabular}{llllll}
\hline Groups comparison & $\begin{array}{l}\text { Mean } \\
\text { difference (I- } \\
\text { J) }\end{array}$ & SD error & Pvalue & 95\% IC \\
\cline { 4 - 6 } & $18,116.66667$ & 6024.70340 & $.040^{*}$ & 814.8320 & Lower bound \\
\hline Laser 30s to Control & $22,356.66667$ & 5152.98597 & $.008^{*}$ & 6657.0263 & $35,418.5013$ \\
Laser 60s to control & -4240.00000 & 4614.85380 & .767 & $-17,993.5245$ & 9513.5245 \\
Laser 30s to Laser 60s & &
\end{tabular}

*: $(P$ value $\leq 0.05)$

Applied tests in these tables: Repeated measured ANOVA, POST HOC

stimulation oxidation of mitochondria and ATP production [24]. Thus,we can claim that our different methodology, which involved the continuous mode of a high-power diode laser, could lead to an increase inATP production in $C$. albicans, which caused less fungal cells to be destroyed.

The results from most of the studies that evaluated the effect of LLLT on C. albicans did not agree with the findings of our study. For example, Maver-Biscaninetal.(2004) compared the effect of laser irradiation at two different wavelengths, $685 \mathrm{~nm}(30 \mathrm{~mW})$ and $830 \mathrm{~nm}(60 \mathrm{~mW})$,with asham laser and an antimicotic agent on 70 patients who had evidence of denture stomatitis [25]. They found that a similar fungicidal effect occurred in both the laser and antimicotic-treated groups, and that the effect was statistically significant in comparison with the placebo group $(P<$ 0.001). This study was the first to research the effect of LLLT on C. albicans without using a photosensitizer [25].

Similarly, Mousaviet al.(2014) Exposed C. albicans cultures to LLLTatenergy levels of $3 \mathrm{~J}, 5 \mathrm{~J}, 10 \mathrm{~J}$, and $20 \mathrm{~J}$ at a wavelength of $685 \mathrm{~nm}(50 \mathrm{~mW})$ and at intensities of $3 \mathrm{~J}$, $5 \mathrm{~J}, 10 \mathrm{~J}, 30 \mathrm{~J}$, and $50 \mathrm{~J}$ at a wavelength of $830 \mathrm{~nm}(400$ $\mathrm{mW})$. The researchers concluded that a laser at an energy level higher than $10 \mathrm{~J}$ at wavelengths of $685 \mathrm{~nm}$ and $830 \mathrm{~nm}$ could significantly reduce the growth of C. albicans colonies [26].

Another researcher evaluated the effect of a $1-\mathrm{W}$ laser and a $0.75-\mathrm{W}$ laser with and without $\mathrm{NaOCl}$ on C. albicans colonies that had been incubated in single-rooted teeth [27]. The results showed that a power of $1 \mathrm{~W}$ combined with $\mathrm{NaOCl}$ caused the greatest reduction in the number of colonies, whereas $\mathrm{NaOCl}$ alone resulted in a minimum reduction in CFUs of C. albicans [27]. In 2010, a study showed that LLLT had a similar fungicidal effect on $C$. albicans compared with photodynamic therapy using toluidine blue, methylene blue, and malachite green [28]. The researchers applied a gallium-aluminumarsenide (Ga-Al-As) laser at a wavelength of $660 \mathrm{~nm}$ with different energy densities of $15.8 \mathrm{~J} / \mathrm{cm}^{2}, 26.3 \mathrm{~J} / \mathrm{cm}^{2}$, and $39.5 \mathrm{~J} / \mathrm{cm}^{2}[28]$.

Maver-Biscanin et al.(2005) discussed the effect of LLLT in non-contact mode on 2 patients with denture stomatitis for different exposure times:5 $\min (830 \mathrm{~nm}$, $3.0 \mathrm{~J} / \mathrm{cm}^{2}$, and $\left.60 \mathrm{~mW}\right)$ and $10 \mathrm{~min}\left(685 \mathrm{~nm}, 3.0 \mathrm{~J} / \mathrm{cm}^{2}\right.$, and $30 \mathrm{~mW}$ ). The researchers showed that LLLT was effective in treating denture stomatitis and reduced the number of colonies and the palatal inflammation [29].

Bassoet al. (2011 investigated the effect of LLLT on biofilms with colonies of Streptococcus mutans and/or C.albicans. Single-species biofilm (SSB) and dualspeciesbiofilm (DSB) were exposed to an indiumgallium-arsenide-phosphide (In-Ga-As-P) diode laser with energy density of $5 \mathrm{~J} / \mathrm{cm}^{2}, 10 \mathrm{~J} / \mathrm{cm}^{2}$, or $20 \mathrm{~J} /$ $\mathrm{cm}^{2}$. (780 nm $\pm 3 \mathrm{~nm}$ and $\left.0.04 \mathrm{~W}\right)$. The study showed that LLLT reduced the bacterial and fungal viability, as well as the growth of the SSB. However, S. mutans was resistant to the LLLT when associated with C. albicans (DSB), although when $C$. albicans was associated with $S$. mutans (DSB), there was a significant decrease in biofilm growth. While the LLLT did not affect the morphology of the microorganisms in the SSB group, the formation of $C$. albicans hyphae was reduced in the DSB. It is believed that the interaction between different microbial species may alter the inhibitory effect of LLLT [30]. Accordingly, it is important to consider that the contamination of $C$. albicans with other microbial species can lead to morphological changes in the fungi, which can affect the results from LLLT.

Carneiro et al. (2016) also studied the effect of LLLT on C.albicans [17]. They used an indium-galliumaluminum-phosphide (In-Ga-Al-P) laser at a wavelength of $685 \mathrm{~nm}$ and a power of $30 \mathrm{~mW}$ and a Ga-Al-As laser at a wavelength of $830 \mathrm{~nm}$ and a power of $40 \mathrm{~mW}$ at energy doses of $6 \mathrm{~J} / \mathrm{cm}^{2}, 8 \mathrm{~J} / \mathrm{cm}^{2}, 10 \mathrm{~J} / \mathrm{cm}^{2}$, and $12 \mathrm{~J} / \mathrm{cm}^{2}$. There was no statistically significant reduction observed in the number of colonies of $C$. albicans; the best result was obtained at6J/ $/ \mathrm{cm}^{2}$ using the $\mathrm{Ga}-\mathrm{Al}$-As laser [17].

A study done in 2016 claimed that the stimulation of polymorphonuclear leukocytes (PMNs) by LLLT led to the production of higher levels of reactive oxygen species (ROS),such ashypochlorite anions $\left(\mathrm{ClO}^{-}\right)$and hydroxyl radicals $(\mathrm{HO} \bullet)$, which enhanced the fungicidal capacity of the treatment against $C$. albicans. PMNs were treated witha laser at a wavelength of $660 \mathrm{~nm}$ or $780 \mathrm{~nm}$ at 40 $\mathrm{mW}$ andincreasing energy levels up to $19.2 \mathrm{~J}$ [18].

In this study, we compared the effect of LLLTwithnystatin treatment on the growth of different concentrations $\left(10^{4}\right.$ viable cells $/ \mathrm{mland} 10^{6}$ viable cells $\left./ \mathrm{ml}\right)$ of $C$. albicans; 
the treatments were given for $30 \mathrm{~s}$ and $60 \mathrm{~s}$. While the nystatin eliminated The $C$. albicans colonies for both concentrations and time periods, surprisingly the LLLT led to an increase in the number of colonies. To the best of our knowledge, this result had never been reported before. According to the results of previous studies, several factors are involved in the effectiveness of LLLT on the growth of $C$. albicans colonies, including modulation frequency, radiant exposure, and other factors such as power, energy level and energy densities [31]. Interestingly, LLLT has reported to have both anti-inflammatory and pro-inflammatory effects. The anti-inflammatory effects of LLLT involve the diminished chemotaxis of PMNs, which affects the site of inflammation. However, somewhat paradoxically, LLLT may also be able to enhance the antimicrobial activity levels of PMNs. These effects were discussed in studies undertaken in 2015 and $2016[18,32]$. The researchers suggested that this mechanism could be one of the reasons for the reduced growth of Candida under LLLT. Furthermore they noted that the antifungal mechanism of LLLT might be related to the thermal effect of photo disruption. It is believed that LLLT destroys the cell wall of a microorganism and causes denatured proteins to accumulate in the cytoplasm. The damage to the microorganism results in cell death. In this situation, the microorganism attempts to maintain homeostasis despite the increasing cellular stress, which subsequently inhibits growth and leads to cell lysis. An alteration in the relationship between microorganism and its cellular substrate may also cause a disruption of the vital activities of microorganisms [30].

In addition to its anti-inflammatory effects, LLLT has pro-inflammatory effects. LLLT promotes wound healing by accelerating the synthesis of collagen and the wound healing time and obtaining tensile strength. These findings indicated that there was an increase in metabolic indices, such as ATP synthesis, fibroblast proliferation, collagen synthesis, and other biomechanical indices of tissues [31].

\section{Conclusion}

Several factors, including the type of laser therapy, cultural conditions, and the type of organism, have significant effects on the results of LLLT on infectious agents. The paradox of LLLT being both a potent anti-inflammatory and a pro-inflammatory agent, as well as the benefits and risks involved in using lasers on infected tissues, must be considered before LLLT can be recommended for use in clinical practice. We believe that further research is required to evaluate the behavior of $C$. albicans and its responses to LLLT under controlled conditions.

\section{Abbreviations}

ANOVA: Analysis of variance; ATP: Adenosine triphosphate; C. albicans: Candida albicans; CFU: Colony-forming units; $\mathrm{ClO}^{-}$: Hypochlorite anions; DSB: Dual-species biofilm; Ga-Al-Ar: Gallium-aluminum-argon;
HO:: Hydroxyl radicals; LLLT: Low-level laser therapy; NaOCl: Sodium hypochlorite; NPar: Nonparametric; PMNs: Polymorphonuclears; ROS: Reactive oxygen species; SCC: Squamus cell carcinoma; SSB: Single-species biofilm

\section{Acknowledgements}

The authors thank Dental research center, Tehran University of Medical Science, Tehran, Iran, for their excellent technical help.

\section{Declarations}

All manuscript submissions to BMC Oral Health must contain a Declarations section which includes a response to each of the mandatory sub-headings listed below.

\section{Authors' contributions}

SN: made substantial contributions to conception and design, acquisition of data, analysis and interpretation of data; NS: involved in drafting the manuscript or revising it critically for important intellectual content; given final approval of the version to be published. MK: made substantial contributions to conception and design, acquisition of data, analysis and interpretation of data; NG: given final approval of the version to be published. Agreed to be accountable for all aspects of the work in ensuring that questions related to the accuracy or integrity of any part of the work are appropriately investigated and resolved. All authors read and approved the final manuscript

\section{Funding}

This study has not any funder.

Availability of data and materials

Not applicable.

Ethics approval and consent to participate Not applicable.

\section{Consent for publication}

In this study there is no details, images, or videos relating to an individual person that which needs to be agreed to publish.

\section{Competing interests}

The authors declare that they have no competing interests.

Received: 11 June 2018 Accepted: 4 June 2019

Published online: 13 June 2019

\section{References}

1. Fabio CA, et al. Use of photodynamic therapy and chitosan for inactivacion of Candida Albicans in a murine model. J Oral Pathol Med. 2016;45:627-33.

2. Pramod J, Jayasree VM. Oropharyngeal candidiasis associated with use of steroid inhaler in a chronic asthmatic patient: case report. Int J Oral MaxilloPathol. 2013:4(3):40-3.

3. Jabra-Rizk MA, Kong EF, Tsui C, Nguyen MH, Clancy CJ, Fidel PL Jr, Noverr M. Candida Albicans pathogenesis: fitting within the host-microbe damage response framework. Infect Immun. 2016;84:2724-39.

4. Sampaio-Maia B, Monteiro-Silva F. Acquisition and maturation of oral microbiome throughout childhood: an update. Dent Res J (Isfahan). 2014;11(3):291-301

5. Ellepola a ANB, Samaranayakeb LP, Khanc ZU. Extracellular phospholipase production of oral Candida Albicans isolates from smokers, diabetics, asthmatics, denture wearers and healthy individuals following brief exposure to polyene, echinocandin and azole antimycotics. Braz J Microbiol. 2016;47(4):911-6.

6. Akpan A, Morgan R. Oral candidiasis. Postgrad Med J. 2002;78(922):455-9.

7. Ohshima T, Kojima Y, Seneviratne CJ, Maeda N. Therapeutic application of Synbiotics, a fusion of probiotics and prebiotics, and Biogenics as a new concept for Oral Candida infections: a mini review. Front Microbiol. 2016;7:10.

8. Richardson MD. Changing Paterns and tredns in systemic fungal infections. J Antimicrob Chemother. 2005;56(1):i5-i11.

9. Frenkel H, Harvey I, Newcombe RG. Oral health care among nursing home residents in Avon. Gerodontology. 2000;17(1):33-8.

10. Jainkittivong A, Aneksuk V, Langlais RP. Oral mucosal lesions in denture wearers. Gerodontology. 2010;27(1):26-32. 
11. Ramage G, Tomsett K, Wickes BL, Lopez-Ribot JL, Redding SW. Denture stomatitis: a role for Candida biofilms. Oral Surg Oral Med Oral Pathol Oral Radiol Endod. 2004;98(1):53-9.

12. Cueto A, Martinez R, Niklander S, Deichler J, Barraza A, Esguep A. Prevalence of oral mucosal lesions in an elderly population in the city of Valparaiso, Chile. Gerodontology. 2013;30(3):201-6.

13. Hammond SM. Biological activity of polyene antibiotics. Prog Med Chem. 1977;14:105-79.

14. Blomgren J, Berggren U, Jontell M. Fluconazole versus nystatin in the treatment of oral candidosis. Acta Odontol Scand. 1998;56(4):202-5.

15. Zomorodian K, Rahimi MJ, Pakshir K, Motamedi M, Ghiasi MR, Rezashah H. Determination of antifungal susceptibility patterns among the clinical isolates of Candida species. J Global Infect Dis. 2011;3(4):357-60.

16. De Bernardis F, Chiani P, Ciccozzi M, Pellegrini G, Ceddia T, D'Offizzi G, et al. Elevated aspartic proteinase secretion and experimental pathogenicity of Candida Albicans isolatesfrom oral cavities of subjects infected with human immunodeficiency virus. Infect Immun. 1996;64(2):466-71.

17. Carneiro VSM, et al. Effect of low-level laser therapy on the fungal proliferation of Candida Albicans. 2016;9695. https://doi.org/10.1117/12.2214269.

18. Cerdeira CD, et al. Low-level laser therapy stimulates the oxidative burst in human neutrophils and increases their fungicidal capacity. J Biophotonics. 2016:9(11-12):1180-1188. 31

19. Basso FG, Oliveria CF, Fontana A, Kurachi C, Bagnato VS, Spolidoria DMP, et al. In-vitro effect of low-level laser therapy on typical Oral microbial biofilms. Braz Dent J. 2011;22(6):502-10.

20. Pfaller MA. Antifungal drug resistance: mechanisms, epidemiology, and consequences for treatment. Am J Med. 2012;125(1 Suppl):S3-13.

21. De Faria IDS, Ueno M, Koga-Ito CY, Urruchi WI, Balducci I, Jorge AOC. Effects of ozonated water on Candida Albicans oral isolates. Brazilian J Oral Sci. 2016;4(14):783-6.

22. Nussbaum EL, Lilge L, Mazzulli T. Effects of 810 nmlaserirradiation on invitrogrowth of bacteria: comparison of continuouswave and frequencymodulatedlight. Lasers Surg Med. 2002;31(5):343-51.

23. Gomes Henriques ÁC, Ginani F, Oliveira RM, Keesen TS, GalvãoBarboza CA, Oliveira Rocha HA, de Castro JF, Della Coletta R, de Almeida Freitas R. Lowlevellaser therapy promotes proliferation and invasion of oral squamous cell carcinoma cells. Lasers Med Sci. 2014;29(4):1385-95.

24. Choi HW, Lee J, Lee S, Choi J, Lee K, Kim BK, Kim GJ. Effects of high intensity laser therapy on pain and function of patients with chronic back pain. J Phys Ther Sci. 2017;29(6):1079-81.

25. Maver-Biscanin M, Mravak-Stipetic M, Jerolimov V, Biscanin A. Fungicidal effect of diodelaserirradiation in patients with denturestomatitis. Lasers Surg Med. 2004;35(4):259-62.

26. S S, Hashemi SJ, Rezaie S, Fateh M, Djavid GE, Zibafar E, Morsali F, Zand N, Alinaghizadeh M, Ataie-Fashtami L. Effects of low-levellaser irradiation on the pathogenicity of Candida Albicans: in-vitro and in vivo study. Photomed Laser Surg. 2014;32(6):322-9.

27. Onay EO, Alikaya C, Seker E. Evaluation of Antifungal Efficacy of Erbium, Chromium: Yttrium-Scandium-Gallium-Garnet Laser AgainstCandidaAlbicans. Photomed Laser Surg. 2010;28(S1):S-73-8.

28. Souza RC, Junqueira JC, Rossoni RD, Pereira CA, Munin E, Jorge AO. Comparison of the photodynamicfungicidalefficacy of methyleneblue, toluidineblue, malachitegreen and low-powerlaserirradiationaloneagainstCandidaAlbicans. Lasers Med Sci. 2010;25(3):385-9.

29. Maver-Biscanin M, Mravak-Stipetic M, Jerolimov V. Effect of low-levellaser therapy on Candida Albicans growth in patients with denture stomatitis. Photomed Laser Surg. 2005;23(3):328-32.

30. Basso F, et al. In-vitro effect of low-levellasertherapy on typicaloralmicrobialbiofilms. Braz Dent J. 2011;22(6):502-10

31. Woodruff $L D$, et al. The efficacy of lasertherapy in woundrepair: a metaanalysis of the literature. Photomed Laser Surg. 2004;22(3):241-7.

32. Burger $E$, et al. Low-level laser therapy to the mouse femur enhances the fungicidal response of neutrophils against Paracoccidioidesbrasiliensis. PLoSNegl Trop Dis. 2015;9(2):e0003541.

\section{Publisher's Note}

Springer Nature remains neutral with regard to jurisdictional claims in published maps and institutional affiliations.

Ready to submit your research? Choose BMC and benefit from:

- fast, convenient online submission

- thorough peer review by experienced researchers in your field

- rapid publication on acceptance

- support for research data, including large and complex data types

- gold Open Access which fosters wider collaboration and increased citations

- maximum visibility for your research: over $100 \mathrm{M}$ website views per year

At BMC, research is always in progress.

Learn more biomedcentral.com/submissions 